\title{
Cortical Thickness of Native Tibetans in the Qinghai-Tibetan Plateau
}

\author{
(D)W. Wei, (D)X. Wang, (D) Q. Gong, (D) M. Fan, and (D). Zhang
}

\section{ABSTRACT}

BACKGROUND AND PURPOSE: High-altitude environmental factors and genetic variants together could have exerted their effects on the human brain. The present study was designed to investigate the cerebral morphology in high-altitude native Tibetans.

MATERIALS AND METHODS: T1-weighted brain images were obtained from 77 Tibetan adolescents on the Qinghai-Tibetan Plateau (altitude, 2300-5300 m) and 80 matched Han controls living at sea level. Cortical thickness, curvature, and sulcus were analyzed by using FreeSurfer.

RESULTS: Cortical thickness was significantly decreased in the left posterior cingulate cortex, lingual gyrus, superior parietal cortex, precuneus, and rostral middle frontal cortex and the right medial orbitofrontal cortex, lateral occipital cortex, precuneus, and paracentral lobule. Curvature was significantly decreased in the left superior parietal cortex and right superior marginal gyrus; the depth of the sulcus was significantly increased in the left inferior temporal gyrus and significantly decreased in the right superior marginal gyrus, superior temporal gyrus, and insular cortex. Moreover, cortical thickness was negatively correlated with altitude in the left superior and middle temporal gyri, rostral middle frontal cortex, insular cortex, posterior cingulate cortex, precuneus, lingual gyrus, and the right superior temporal gyrus. Curvature was positively correlated with altitude in the left rostral middle frontal cortex, insular cortex, and middle temporal gyrus. The depth of the sulcus was negatively correlated with altitude in the left lingual gyrus and right medial orbitofrontal cortex.

CONCLUSIONS: Differences in cortical morphometry in native Tibetans may reflect adaptations related to high altitude.

ABBREVIATIONS: $\mathrm{DMN}=$ default mode network; $\mathrm{HA}=$ high altitude; $\mathrm{PCC}=$ posterior cingulate cortex; PPARA = peroxisome proliferator-activated receptor $\alpha$

$\mathrm{T}$ he Qinghai-Tibetan Plateau is one of the most extreme environments inhabited by humans. High-altitude (HA) natives have developed distinctive biologic characteristics in respiratory and circulatory functions, ${ }^{1,2}$ hemoglobin concentration, ${ }^{3}$ arterial oxygen saturation, ${ }^{4}$ energy metabolism, ${ }^{5}$ and genes ${ }^{6}$ to offset the stresses of HA environmental factors. Previous studies have re-

Received August 2, 2016; accepted after revision October 24

From the MRI Center (W.W.), First Affiliated Hospital of Xiamen University, Xiamen, China; Institute of Brain Disease and Cognition (W.W., J.Z.), Medical College of Xiamen University, Xiamen, China; Department of Neurology (X.W.), Affiliated Hospital of Hangzhou Normal University, Hangzhou, China; Huaxi Magnetic Resonance Research Center (Q.G.), West China Hospital, Sichuan University, Chengdu, China; and Department of Cognitive Sciences (M.F.), Institute of Basic Medical Sciences, Beijing, China.

This work was supported by National Science Foundation of China (grant numbers: 81171324 and 81471630) and the National Key Project (2012CB518200).

Please address correspondence to Jiaxing Zhang, MD, Department of Physiology, Medical College of Xiamen University, Xiamen, 361005, China; e-mail: zhangjiaxing@xmu.edu.cn

- Indicates open access to non-subscribers at www.ajnr.org

http://dx.doi.org/10.3174/ajnr.A5050 vealed the adaptation of the cerebral glucose metabolic rate ${ }^{7}$ in HA Quechua natives and the adaptation of cerebral autoregulation in HA Himalayan natives ${ }^{8}$ and Ethiopian natives. ${ }^{9}$ However, existing studies provided no assessments of the cerebral structures in HA natives.

The brain is one of the organs in the body with the highest oxygen consumption and thus is particularly vulnerable to hypoxia. ${ }^{10}$ In contrast, cold weather at a HA may result in hypothermia, which has been shown to have a neuroprotective effect against hypoxic damage. ${ }^{11,12}$ Hypobaria at a HA could also be a factor contributing to brain lesions because it has been proved to induce white matter and cortical thickness impairment. ${ }^{13-15}$ Environmental ultraviolet rays can cause neuronal damage in the visual system and brain. ${ }^{16-18}$ Therefore, these HA environmental factors together could have exerted their effect on brain development.

Many present day native Tibetans on the Qinghai-Tibetan Plateau are the descendants of colonizers who arrived, at most, 25,000 years ago. ${ }^{19}$ Genetic adaptations at HA have been found in 
the native Tibetans. Unique to Tibetans are the variants of genes within the hypoxia-inducible factor pathway, including Egl 9 homolog 1 (EGLN1), endothelial PAS domain protein 1 (EPAS1), and peroxisome proliferator-activated receptor $\alpha$ (PPARA), key genes in the oxygen homeostasis system at all altitudes. ${ }^{20}$ Among these genes, PPARA is involved in neuronal proliferation, differentiation, and apoptosis ${ }^{21}$ and neuroprotection against oxidative stress. $^{22}$ Genetic variants may also play a role in brain development at a HA.

In previous studies, we have investigated the brain acclimatization to HA in the Han immigrant descendants on the QinghaiTibetan Plateau ${ }^{23}$ and in the lowlanders immigrating to the Qinghai-Tibetan Plateau for several days to several years. ${ }^{24,25} \mathrm{We}$ found that HA acclimatization was associated with brain structural and functional modifications. Therefore, we hypothesized that native Tibetans could have developed brain adaptations to HA under the combined actions of both environmental factors and genetic variants. To test this hypothesis, we investigated the cerebral morphology of 77 healthy Tibetan adolescents living at different altitudes, with 80 sea-level Han adolescents as controls.

\section{MATERIALS AND METHODS \\ Subjects}

Seventy-seven healthy native Tibetans (34 males and 43 females, 14-18 years of age) living in the southeast Tibet Autonomous Region (southeast Nagqu, Xigaze, Lasa, Nyingchi, and Chamdo) (altitude, 2300-5300 m) were recruited. Their ancestors were all native Tibetans living on the Qinghai-Tibetan Plateau. They were without any prior descent to the lowlands or ascent to higher altitudes. All had a normal body mass index. They were all 10th grade students and had been enrolled in a high school at Chengdu (altitude, $<400 \mathrm{~m}$ ) for half a month. The control subjects were 80 (34 males and 46 females, $14-18$ years of age) adolescents living at sea level (altitude, $<50 \mathrm{~m}$ ), matched with the native Tibetans by sex, age, and education. Subjects were excluded if they had a history of mountain sickness, neurologic disorder, or head injury. The experimental protocol was approved by the Research Ethics Review Board of Xiamen University. Procedures were fully explained, and all subjects provided written informed consent before participating in the study.

\section{MR Imaging Data Acquisition}

Brain images were obtained on the same model 3T Signa Excite MR imaging system (GE Healthcare, Milwaukee, Wisconsin) at the Huaxi Magnetic Resonance Research Center, West China Hospital, Chengdu, China, and at the MR Imaging Center, First Affiliated Hospital of Xiamen University, Xiamen, China. Parameters for the T1-weighted MPRAGE sequences were the following: $\mathrm{TR} / \mathrm{TE}=1900 / 2.48 \mathrm{~ms}, \mathrm{FOV}=25 \times 25 \mathrm{~cm}^{2}, \mathrm{NEX}=1$, matrix $=$ $512 \times 256$, section thickness $=1.0 \mathrm{~mm}$. Conventional 2D T1 and T2 images were also obtained and examined for any incidental findings. Data analyses were conducted by 2 researchers who were blinded to the status of subjects.

\section{FreeSurfer Analysis}

FreeSurfer (Version 5.1.0; http://surfer.nmr.mgh.harvard.edu) was used for cortical thickness, curvature, and sulcus analyses.
The process consisted of the removal of nonbrain tissue, mapping to Talairach-like space, and segmentation of the gray/white matter and pial boundaries. These maps of measurements were obtained by reconstructing representations of the GM/white matter boundary and the white matter boundary to the GM/CSF boundary and then calculating the closest distance from those surfaces at each vertex on the tessellated surfaces. All subject data were resampled to the FreeSurfer default common surface template by using a high-resolution surface-based averaging technique that aligned cortical folding patterns. Finally, the surface data were spatial smoothed by using a Gaussian kernel of 10-mm full width at half maximum. Regional variations of the cortical thickness, curvature, and sulcus were compared by using an independent samples $t$ test, with age, sex, and education as covariates. The statistical parametric map was generated at $P<.05$ (false discovery rate-corrected for multiple comparisons).

\section{Correlation Analysis}

The correlations of cerebral structural measurements with altitude were analyzed, with age and sex as covariates. The false discovery rate of $P<.05$ was applied to correct for multiple comparisons.

\section{RESULTS}

\section{Cortical Thickness, Curvature, and Depth of the Sulcus}

Compared with controls, the significant changes of cerebral structural measurements in native Tibetans are shown in Fig 1. Cortical thickness was significantly decreased in the left posterior cingulate cortex (PCC), lingual gyrus, superior parietal cortex, precuneus, and rostral middle frontal cortex and the right medial orbitofrontal cortex, lateral occipital cortex, precuneus, and paracentral lobule (Table 1. Furthermore, curvature was significantly decreased in the left superior parietal cortex and right superior marginal gyrus. Finally, the depth of the sulcus was significantly increased in the left inferior temporal gyrus and significantly decreased in the right superior marginal gyrus, superior temporal gyrus, and insular cortex.

\section{Correlations}

The significant correlations of cerebral structural measurements with altitude in native Tibetans are shown in Fig 2. Cortical thickness was negatively correlated with altitude in the left superior and middle temporal gyri, rostral middle frontal cortex, PCC, precuneus, lingual gyrus, insular cortex, and right superior temporal gyrus (Table 2). Curvature was positively correlated with altitude in the left rostral middle frontal cortex, insular cortex, and middle temporal gyrus. The depth of the sulcus was negatively correlated with altitude in the left lingual gyrus and right medial orbitofrontal cortex.

Figure 3 indicates the overlaps of brain between the regions showing decreases of cortical thickness and those showing correlation between cortical thickness and altitude. These regions included the left PCC, precuneus, lingual gyrus, and rostral middle frontal cortex.

\section{DISCUSSION}

Our study is the first to reveal the cerebral characteristics of native Tibetans living on the Qinghai-Tibetan Plateau. Adaptations of Tibetans to HA were associated with structural modifications in 


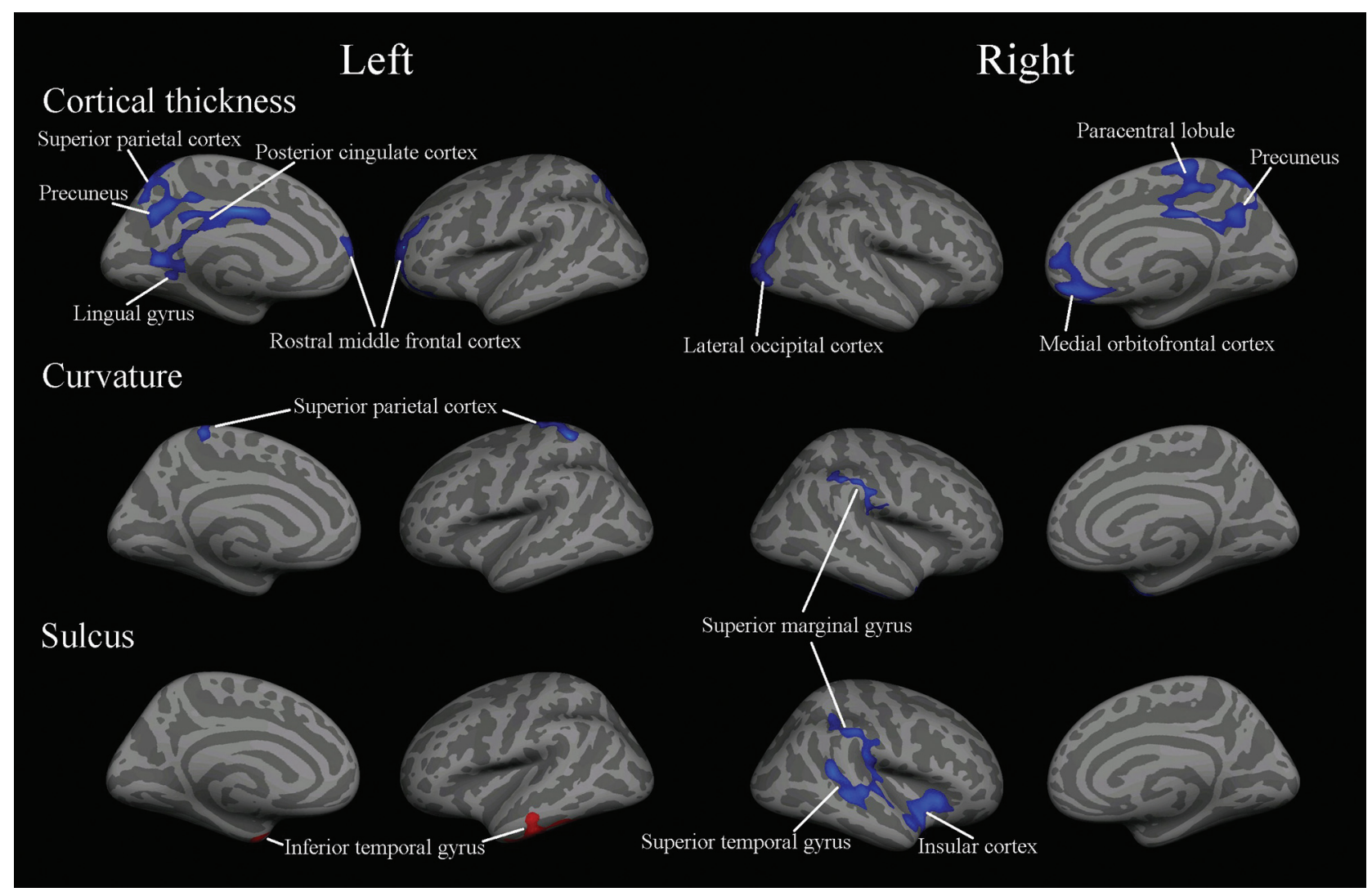

FIG 1. Regions showing changes of cortical measurements in native Tibetans compared with the sea-level Han controls $(P<.05$, false discovery rate-corrected for multiple comparisons). Blue indicates a decrease; red, an increase.

\begin{tabular}{|c|c|c|c|c|c|}
\hline \multirow[b]{2}{*}{ Areas } & \multirow{2}{*}{$\begin{array}{c}\text { Volume } \\
\left(\mathrm{mm}^{3}\right)\end{array}$} & \multicolumn{3}{|c|}{$\begin{array}{c}\text { MNI } \\
\text { Coordinate }\end{array}$} & \multirow[b]{2}{*}{$P$ (Peak } \\
\hline & & $\mathbf{x}$ & y & z & \\
\hline \multicolumn{6}{|l|}{ Left } \\
\hline Posterior cingulate cortex/lingual gyrus & 1467 & -3.7 & -8.5 & 33.8 & 3.651 \\
\hline Superior parietal cortex/precuneus & 1815 & -8.6 & -68.1 & 56.0 & 2.571 \\
\hline Rostral middle frontal cortex & 1575 & -31.2 & 36.9 & 22.6 & 1.878 \\
\hline \multicolumn{6}{|l|}{ Right } \\
\hline Lateral occipital cortex & 2149 & 26.4 & -83.9 & 14.4 & 3.081 \\
\hline Precuneus/paracentral lobule & 2200 & 7.7 & -61.8 & 58.2 & 2.583 \\
\hline Medial orbitofrontal cortex & 1366 & 8.4 & 47.6 & -13.8 & 3.296 \\
\hline
\end{tabular}

paracentral lobule, PCC, and precuneus and increases of cortical thickness in the orbitofrontal cortex, superior parietal cortex, inferior temporal gyrus, and lingual gyrus. ${ }^{25}$ Moreover, compared with Tibetan adolescents who had lived at sea level for 4 years, the Tibetan adolescents who lived at a HA all the time showed decreases of GM volume in the superior parietal cortex and insular cortex. ${ }^{26}$

\section{Effects of Environmental Factors on Brain Structural Development}

cortical thicknesses, curvature, and the sulcus. Mainly in the left hemisphere, the cortical structures were significantly correlated with altitude; moreover, with increasing altitude, native Tibetans had a decrease of regional cortical thickness, while they had an increase of cortical folding in terms of curvature. The regions showing decreases of cortical thickness and those showing correlations between cortical thickness and altitude overlapped in the left PCC, precuneus, lingual gyrus, and rostral middle frontal cortex.

The changed brain regions in the native Tibetans were in agreement with those found in our previous studies on Han immigrants living on the Qinghai-Tibetan Plateau. For example, Han immigrant descendants at HA showed decreases of GM volume in the cingulate cortex, rostral middle frontal cortex, lingual gyrus, and anterior insular cortex. ${ }^{23}$ Adult immigrants who lived at a HA for 2 years showed decreases of cortical thickness in the

In native Tibetans, there were significant correlations between regional cortical measurements and altitude, suggesting that HA environmental factors influence brain development. The effects of HA environmental factors on brain development have been detected in Tibetan adolescents who were born and raised on the Qinghai-Tibetan Plateau compared with Tibetan adolescents who had lived at sea level during the past 4 years. ${ }^{26}$

Cortical changes may be induced by hypoxia. For example, cerebral edema was found after acute exposure to normobaric hypoxia. ${ }^{27}$ In agreement with the present findings, damage of GM in the cingulate cortex, temporal gyrus, and insular cortex has been detected in patients with hypoxia with chronic obstructive pulmonary disease. ${ }^{28}$ The changed cerebral circulation may be attributed to temporal and posterior brain structural alterations shown in the present study. The vertebral artery supplies blood to 


\section{Left}

\section{Right}

\section{Cortical thickness}

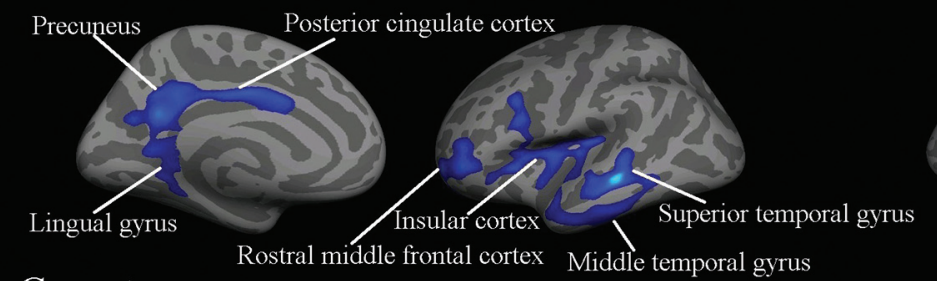

\section{Curvature}

Rostral middle frontal cortex Middle temporal gyrus
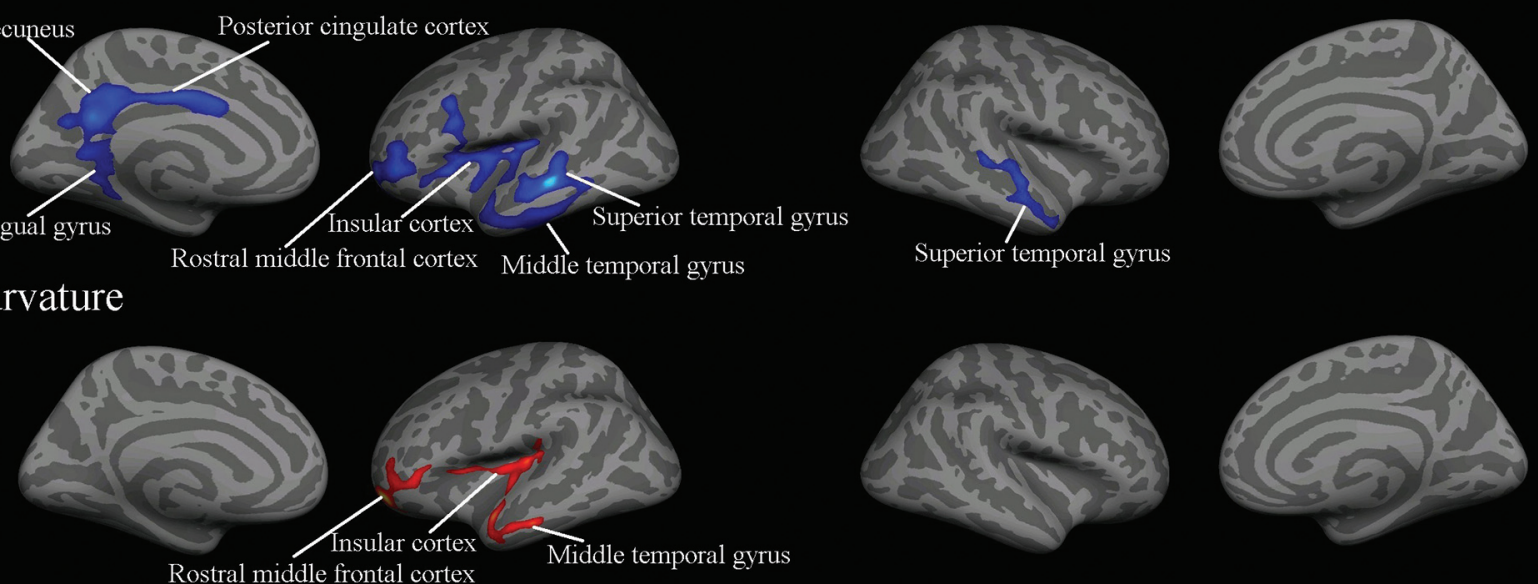

Sulcus
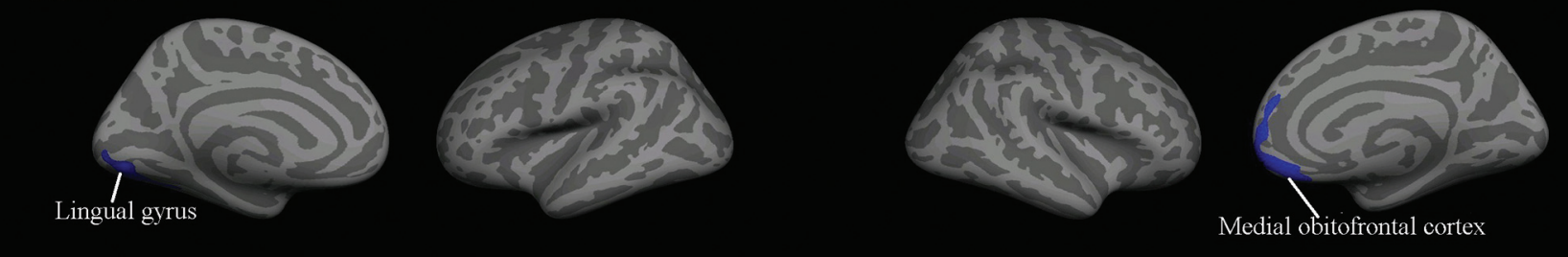

FIG 2. Regions in which the cortical measurements in native Tibetans showed significant correlations with altitude $(P<.05$, false discovery rate-corrected for multiple comparisons). Blue indicates a negative correlation; red, a positive correlation.

Table 2: Information of regions in which cortical thickness showed correlation with altitude in Tibetans

\begin{tabular}{|c|c|c|c|c|c|}
\hline \multirow[b]{2}{*}{ Areas } & \multirow{2}{*}{$\begin{array}{l}\text { Volume } \\
\left(\mathrm{mm}^{2}\right)\end{array}$} & \multicolumn{3}{|c|}{$\begin{array}{c}\text { MNI } \\
\text { Coordinate }\end{array}$} & \multirow[b]{2}{*}{$P($ Peak $)$} \\
\hline & & $x$ & $y$ & z & \\
\hline \multicolumn{6}{|l|}{ Left } \\
\hline Superior/middle temporal gyrus & 3150 & -49.0 & -32.6 & -9.2 & 4.949 \\
\hline $\begin{array}{l}\text { Precuneus/posterior cingulate cortex/lingual } \\
\text { gyrus }\end{array}$ & 2510 & -9.4 & -55.9 & 22.5 & 3.519 \\
\hline Rostral middle frontal cortex & 1431 & -23.8 & 51.8 & -4.9 & 3.426 \\
\hline Insular cortex & 2543 & -27.8 & 24.3 & 5.7 & 2.445 \\
\hline \multicolumn{6}{|l|}{ Right } \\
\hline Superior temporal gyrus & 1174 & 56.6 & -13.1 & -4.7 & 2.134 \\
\hline
\end{tabular}

Note:-MNI indicates Montreal Neurological Institute.

these 2 parts of the brain. Willie et $\mathrm{al}^{29}$ found that with hypoxia, the relative increase in vertebral artery blood flow was $50 \%$ greater than in the other vessels. Ogoh et $\mathrm{al}^{30}$ found that the internal carotid artery blood flow was unchanged, while the vertebral artery blood flow was significantly increased during acute hypoxia. Feddersen et $\mathrm{al}^{31}$ found that in mountaineers during ascent to $5050 \mathrm{~m}$, the cerebral blood flow velocity was decreased in the posterior cerebral arteries. Moreover, hypoxia-induced alteration of cerebral blood flow patterns was found in the posterior brain in patients with hypoxia and obstructive sleep apnea, which included the lingual gyrus, parietal lobule, precuneus, temporal cortex, and insular cortex. ${ }^{32}$ Recently, Lawley et $\mathrm{al}^{33}$ found that 2 hours of hypoxia caused an expected increase in frontal cortical gray matter perfusion but unexpected perfusion decreases predominantly in the PCC. After 10 hours in hypoxia, the decreased blood flow became more pronounced and widespread. They fur- ther confirmed that these reductions in cerebral blood flow from hypoxia were related to vasoconstrictions.

Hypobaria at HA could be another important factor contributing to brain alterations. Acute mountain sickness scores were higher, ${ }^{34}$ and visual sensitivities were lower ${ }^{35}$ in hypobaric than in normobaric hypoxia. Studies on U-2 pilots showed that hypobaria was associated with a change of white matter hyperintensity $^{14,36}$ and with the reduction of cortical thickness. ${ }^{15}$ Moreover, exposure to hypobaria after traumatic brain injury worsened brain function. $^{37}$

Cold ambient temperature at a HA may result in hypothermia. Mild hypothermia is associated with decreased ventricular function, oxygen extraction, and microvascular flow. ${ }^{38}$ During hypoxia, hypothermia has been shown to have a neuroprotective effect against hypoxic encephalopathy. ${ }^{12}$ Moreover, hypothermia treatment in an animal stroke model reduced infarct size and improved neurologic behavior. ${ }^{11}$

The decrease of visual cortical thickness in the present study may be an outcome of ultraviolet radiation at HA. Ultraviolet light has been shown to alter neuronal activity in the cortical structures involved in visual processing. ${ }^{39}$ Environmental doses of ultraviolet rays can induce apoptosis in the retina and lamina ganglionaris within the visual system and in the brains of invertebrate crustaceans. ${ }^{16-18}$ 


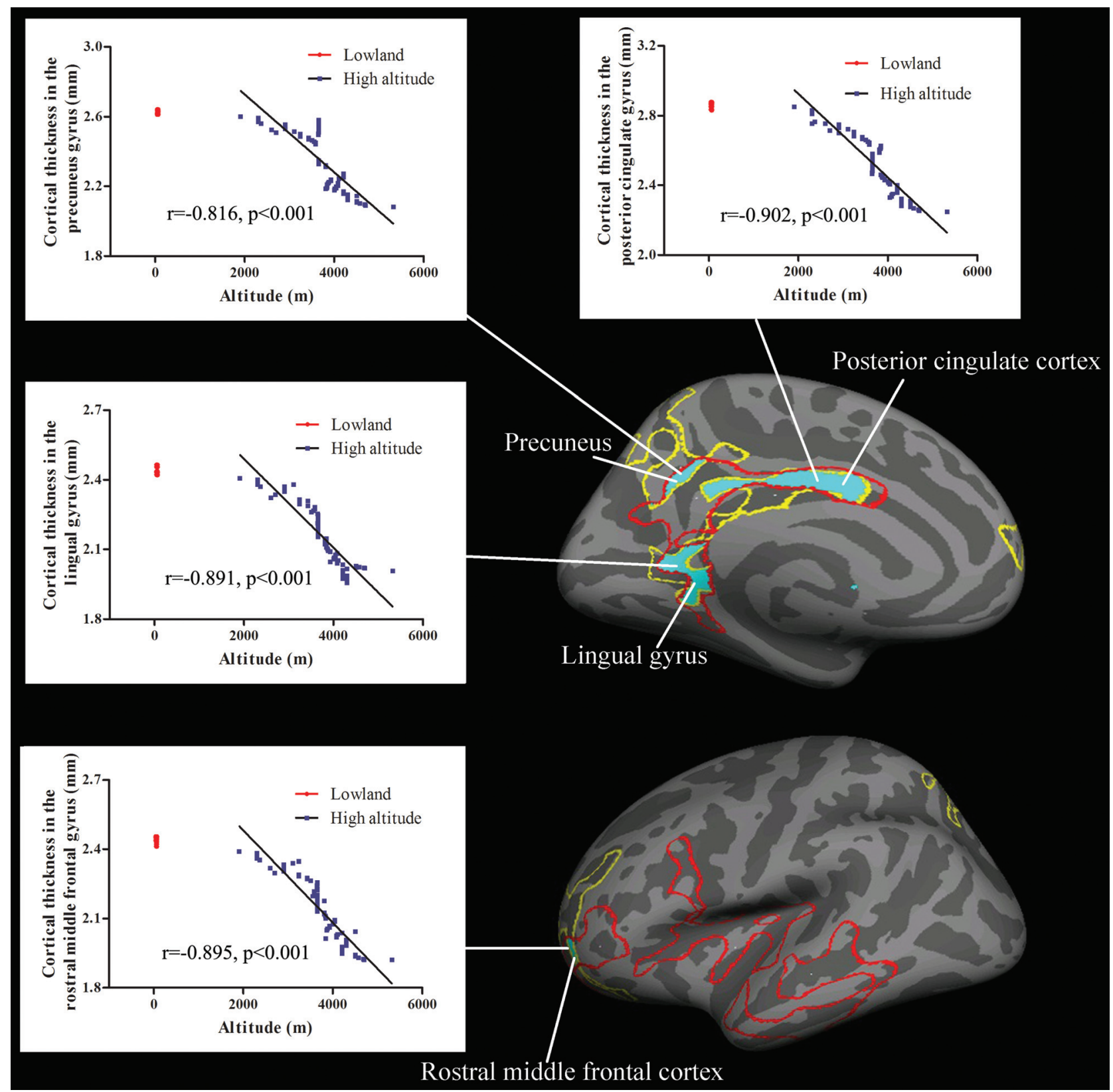

FIG 3. Tibetan brain overlaps (blue areas) between the regions showing significant decreases of cortical thickness (yellow line) and those showing correlations between cortical thickness and altitude (red line). For each correlation diagram, 80 overlapped red dots indicate the cortical thickness values in the sea-level controls. Blue dots indicate that the cortical thickness values in 77 Tibetans were significantly correlated with altitude.

\section{Effects of Genes on Brain Structural Development}

The results of the present study obtained from native Tibetans showed some differences from those found in the Han immigrant descendants, ${ }^{23}$ which suggest that genes may play a role in Tibetan brain development. A recent study discovered genetic selection on the PPARA in HA native Tibetans on the Qinghai-Tibetan Plateau through comparing them with Chinese and Japanese lowland populations. ${ }^{20}$ PPARA is expressed in the brain. ${ }^{21,40}$ It is involved in neuronal proliferation, differentiation, and apoptosis. ${ }^{21,41}$ PPARA encodes the fatty acid-activated transcription factors and fatty acid oxidation regulators; thus, it may affect brain structure through control of energy homeostasis. ${ }^{42,43}$ PPARA is also involved in angiogenesis, ${ }^{44}$ which may contribute to the GM change. Moreover, during hypoxia, PPARA supports a role in neuroprotection against oxidative stress. ${ }^{22}$

\section{Gene or Environment: Which One Determines Brain Structure?}

Reduced psychomotor speed has been tested in the subjects (6-16 years of age) of mixed-ethnic background (including Native American, European, or African ancestries who immigrated to HA during different periods) who were born and raised at HAs. ${ }^{45}$ For the proportion of Native Americans, Europeans, and Africans, genetic admixture with reduced psychomotor speed was comparable across altitude groups; therefore, chronic hypoxic exposure rather than genetic inheritance appears to affect brain 
function development at HA. However, pulmonary function (forced expiratory volume and forced vital capacity) measures were greater in the HA natives compared with the lowland natives born and raised at HAs; this finding suggests a genetic effect. ${ }^{46}$ In contrast, these 2 pulmonary measures were similar in HA natives and sea-level natives at lowland; this finding suggests that the genetic potential for larger lung volumes at HA depended on the developmental exposure to HA. In summary, results from these studies emphasized the importance of developmental adaptations to HA.

\section{Implications for the Changes in Cortical Structural Measurements}

In our study, decreases of cortical thickness in the medial orbitofrontal cortex, PCC, lingual gyrus, and precuneus; a decrease of curvature in the superior parietal cortex; and a decrease of the depth of the sulcus in the temporal cortices were detected. These regions are core areas of the resting-state brain default mode network (DMN) in humans. ${ }^{47,48}$ The impairment of GM structures may contribute to reduced neuronal activity. Previous multimodal neuroimaging studies have shed light on this functionstructure association, underlining cognition, aging, disease, and behavior. ${ }^{49}$ The changed activity within the DMN in response to chronic stress exposure has been found in humans ${ }^{50}$ and animals. ${ }^{51}$ The impairment of cortical structures in HA Tibetans is likely to reflect the stress-induced atrophic effects in cortical regions. Cortical atrophy within the DMN may reduce the brain response to HA environmental stress. Because regions within the DMN exert forebrain modulation over visceral responses mediated via the hypothalamus and brain stem, structural and functional changes within these circuits may contribute to modulations in autonomic and neuroendocrine functions associated with HA adaptations.

Tibetan college students were found to have higher levels of negative emotional expressivities such as fear, sadness, and anger in comparison with Han, Uighur, Hui, and Mongolian students. ${ }^{52}$ The Cattell 16 Personality Factor Questionnaire revealed that Tibetan adolescents had lower stability, persistence, independence, and self-discipline and higher extroversion and excitability than Han adolescents. ${ }^{53,54}$ The findings of the Eysenck Personality Questionnaire and Trait Coping Style Questionnaire suggested that Tibetan adolescents had higher neuroticism, introversion, and psychoticism and lower concealment than Han adolescents. ${ }^{55}$ In humans, the DMN is thought to support a variety of self-referential functions and mind-wandering. ${ }^{56}$ Anxiety disorders and high trait anxiety are associated with decreased functioning of the DMN. ${ }^{57}$ The precuneus is implicated in social and emotional functions, especially among individuals with neuroticism. ${ }^{58}$ The left posterior and middle cingulate cortices and precuneus were found to be negatively correlated with neuroticism. ${ }^{59}$ The ventral medial prefrontal (orbitofrontal) cortex of the DMN functions as a sensory-visceromotor link concerned with social behavior, mood control, and motivational drive, all of which are important components of an individual's personality. ${ }^{48}$ Therefore, a changed DMN may explain why Tibetan adolescents had personality traits distinct from those of the Han adolescents.

The decreases of cortical thickness in the PCC and lingual gyrus may be related to visual deficits at HA. The poor visual performances were consistent and prominent problems in the HA immigrants, such as the sea-level college students after 7 months of study at moderate altitudes, ${ }^{60}$ and in the HA Han immigrant descendants. ${ }^{61}$ The PCC and lingual gyrus have direct anatomic connectivities with the visual striate cortices. ${ }^{62}$ The PCC lies at the parietomedial temporal visual stream pathway. ${ }^{63}$ It is activated by visual perception, attention, and motion. ${ }^{64-66}$ The lesions of the PCC produce an impairment in visual discrimination learning ${ }^{67}$ and a decrease of resting-state functional connectivity in the PCC, which is indicated by severe myopia. ${ }^{68}$ The lingual gyrus is a part of the occipitotemporal pathway that engages in object drawing ${ }^{69}$ and is activated by visuospatial navigation ${ }^{70}$ and angle discrimination tasks. ${ }^{71} \mathrm{GM}$ volume in the right lingual cortex has been proved to have a positive correlation with visual reproduction, ${ }^{72}$ while GM atrophy in this area was associated with visual hallucinations. ${ }^{73}$

The decreased depth of the anterior insular sulcus and damage to the ventral medial prefrontal cortex in the present study support the hypothesis that these 2 regions are needed to process the perturbation of the homeostatic balance in extreme environments. ${ }^{48,74}$ Because the lesions in the insular cortex have been proved to disrupt representation of internal states that underpin motivation, ${ }^{75}$ the changes of the anterior insular cortex may also be related to the blunted hypoxic ventilatory response in HA residents. $^{76}$

\section{Limitations}

There are several limitations to our study. First, brain images were obtained by using 2 MR imaging scanners. However, several studies have confirmed that the MR imaging scanner field strength, manufacturer, machine upgrade, and pulse sequence ${ }^{77}$ and the different postprocessing algorithms applied to the images acquired from different MR imaging systems ${ }^{78}$ have little effect on the reliability of cortical thickness measurements.

Second, the Tibetan subjects had moved to the lowlands for 1-15 days, which would have an influence on cerebral blood flow. However, given the previous investigations, this effect may be slight after residing at sea level for such a short time. For example, when HA adult natives descended to sea level for several weeks, their cardiac functions remained unchanged. ${ }^{79,80}$

Third, the interethnic difference of brain structure can be large. Brain morphologic differences between populations of different origins have been found in whole-brain and region-specific volume. ${ }^{81}$ Future study should compare the interethnic difference of brain structures between Tibetans and Han populations at lowland.

Fourth, Tibetans have been living on the Qinghai-Tibetan Plateau and have developed a unique culture and language. The lifestyle of the Tibetans was different from that in the lowlands, for example, in the absence of crowds, which could have affected the subjects' emotional well-being. Moreover, diet was likely to be an important factor for the observed brain changes.

\section{CONCLUSIONS}

Native Tibetans have developed brain structural adaptations that enable their successful existence in the HA environment. The al- 
terations of cortical structure in native Tibetans were mainly located in the resting-state brain DMN and were in agreement with those found in the Han immigrants on the Qinghai-Tibetan Plateau. Brain structural modifications may be derived from the interaction between genetic and environmental factors. Future study is need to test the personality traits, body homeostasis, and cognition and clarify the neuronal mechanisms of the Tibetans.

Disclosures: Ming Fan—RELATED: Grant: National Key Project, Comments: grant number 2012CB518200. Jiaxing Zhang—RELATED: Grant: National Science Foundation of China and National Key Project, Comments: grant Nos. 81171324 and 81471630.

\section{REFERENCES}

1. Houston CS, Riley RL. Respiratory and circulatory changes during acclimatization to high altitude. Am J Physiol 1947;149:565-88 Medline

2. Lahiri S, DeLaney RG, Brody JS, et al. Relative role of environmental and genetic factors in respiratory adaptation to high altitude. $\mathrm{Na}$ ture 1976;261:133-35 CrossRef Medline

3. Beall CM, Reichsman AB. Hemoglobin levels in a Himalayan high altitude population. Am J Phys Anthropol 1984;63:301-06 CrossRef Medline

4. Niermeyer S, Yang P, Shanmina, et al. Arterial oxygen saturation in Tibetan and Han infants born in Lhasa, Tibet. N Engl J Med 1995; 333:1248-52 CrossRef Medline

5. Murray AJ. Energy metabolism and the high-altitude environment. Exp Physiol 2016;101:23-27 CrossRef Medline

6. Yi X, Liang Y, Huerta-Sanchez E, et al. Sequencing of $\mathbf{5 0}$ human exomes reveals adaptation to high altitude. Science 2010;329:75-78 CrossRef Medline

7. Hochachka PW, Clark CM, Brown WD, et al. The brain at high altitude: hypometabolism as a defense against chronic hypoxia? J Cereb Blood Flow Metab 1994;14:671-79 CrossRef Medline

8. Jansen GF, Krins A, Basnyat B, et al. Role of the altitude level on cerebral autoregulation in man resident at high altitude. $J$ Appl Physiol (1985) 2007;103:518-23 Medline

9. Claydon VE, Gulli G, Slessarev M, et al. Cerebrovascular responses to hypoxia and hypocapnia in Ethiopian high altitude dwellers. Stroke 2008;39:336-42 CrossRef Medline

10. Hadanny A, Efrati S. Oxygen: a limiting factor for brain recovery. Crit Care 2015;19:307 CrossRef Medline

11. Gao XY, Huang JO, Hu YF, et al. Combination of mild hypothermia with neuroprotectants has greater neuroprotective effects during oxygen-glucose deprivation and reoxygenation-mediated neuronal injury. Sci Rep 2014;4:7091 CrossRef Medline

12. Kvistad CE, Thomassen L, Waje-Andreassen U, et al. Body temperature and major neurological improvement in tPA-treated stroke patients. Acta Neurol Scand 2014;129:325-29 Medline

13. Coppel J, Hennis P, Gilbert-Kawai E, et al. The physiological effects of hypobaric hypoxia versus normobaric hypoxia: a systematic review of crossover trials. Extrem Physiol Med 2015;4:2 CrossRef Medline

14. McGuire SA, Sherman PM, Wijtenburg SA, et al. White matter hyperintensities and hypobaric exposure. Ann Neurol 2014;76:719-26 CrossRef Medline

15. Simmons D, Bursaw A, Sherman P, et al. Repeated exposure to hypobaria in $\mathrm{U} 2$ pilots is associated with reduced aggregate cortical thickness. Neurology 2015;84(suppl):P4.161

16. Hollmann G, Linden R, Giangrande A, et al. Increased p53 and decreased $\mathrm{p} 21$ accompany apoptosis induced by ultraviolet radiation in the nervous system of a crustacean. Aquati Toxicol 2016;173:1-8 CrossRef Medline

17. Miguel NC, Meyer-Rochow VB, Allodi S. Ultrastructural study of first and second order neurons in the visual system of the crab Ucides cordatus following exposure to ultraviolet radiation. Micron 2002;33:627-37 Medline
18. Miguel NC, Wajsenzon IJ, Takiya CM, et al. Catalase: Bax and p53 expression in the visual system of the crab Ucides cordatus following exposure to ultraviolet radiation. Cell Tissue Res 2007;329: 159-68 CrossRef Medline

19. Aldenderfer MS. Moving up in the world. American Scientist 2003; 91:542-49

20. Simonson TS, Yang Y, Huff CD, et al. Genetic evidence for highaltitude adaptation in Tibet. Science 2010;329:72-75 CrossRef Medline

21. Cimini AM, Cerù MP. Emerging roles of peroxisome proliferatoractivated receptors (PPARs) in the regulation of neural stem cells proliferation and differentiation. Stem Cell Rev 2008;4:293-303 CrossRef Medline

22. Fidaleo M, Fanelli F, Ceru MP, et al. Neuroprotective properties of peroxisome proliferator-activated receptor alpha (PPAR $\alpha)$ and its lipid ligands. Curr Med Chem 2014;21:2803-21 CrossRef Medline

23. Zhang J, Yan X, Shi J, et al. Structural modifications of the brain in acclimatization to high-altitude. PLoS One 2010;5:e11449 CrossRef Medline

24. Zhang H, Lin J, Sun Y, et al. Compromised white matter microstructural integrity after mountain climbing: evidence from diffusion tensor imaging. High Alt Med Biol 2012;13:118-25 CrossRef Medline

25. Zhang J, Zhang H, Li J, et al. Adaptive modulation of adult brain gray and white matter to high altitude: structural MRI studies. PLoS One 2013;8:e68621 CrossRef Medline

26. Zhang J, Zhang H, Chen J, et al. Structural modulation of brain development by oxygen: evidence on adolescents migrating from high altitude to sea level environment. PLoS One 2013;8:e67803 CrossRef Medline

27. Kallenberg K, Bailey DM, Christ S, et al. Magnetic resonance imaging evidence of cytotoxic cerebral edema in acute mountain sickness. J Cereb Blood Flow Metab 2007;27:1064-71 Medline

28. Zhang H, Wang X, Lin J, et al. Grey and white matter abnormalities in chronic obstructive pulmonary disease: a case-control study. BMJ Open 2012;2:e000844 CrossRef Medline

29. Willie CK, Macleod DB, Shaw AD, et al. Regional brain blood flow in man during acute changes in arterial blood gases. J Physiol 2012;590: 3261-75 CrossRef Medline

30. Ogoh S, Sato K, Nakahara H, et al. Effect of acute hypoxia on blood flow in vertebral and internal carotid arteries. Exp Physiol 2013;98: 692-98 CrossRef Medline

31. Feddersen B, Neupane $P$, Thanbichler F, et al. Regional differences in the cerebral blood flow velocity response to hypobaric hypoxia at high altitudes. J Cereb Blood Flow Metab 2015;35:1846-51 CrossRef Medline

32. Baril AA, Gagnon K, Arbour C, et al. Regional cerebral blood flow during wakeful rest in older subjects with mild to severe obstructive sleep apnea. Sleep 2015;38:1439-49 CrossRef Medline

33. Lawley JS, Macdonald JH, Oliver SJ, et al. Unexpected reductions in regional cerebral perfusion during prolonged hypoxia. J Physiol 2016 Aug 9. [Epub ahead of print] CrossRef Medline

34. DiPasquale DM, Strangman GE, Harris NS, et al. Hypoxia, hypobaria, and exercise duration affect acute mountain sickness. Aerosp Med Hum Perform 2015;86:614-19 CrossRef Medline

35. Degache F, Larghi G, Faiss R, et al. Hypobaric versus normobaric hypoxia: same effects on postural stability? High Alt Med Biol 2012; 13:40-45 CrossRef Medline

36. McGuire S, Sherman P, Profenna L, et al. White matter hyperintensities on MRI in high-altitude U-2 pilots. Neurology 2013;81:729-35 CrossRef Medline

37. Skovira JW, Kabadi SV, Wu J, et al. Simulated aeromedical evacuation exacerbates experimental brain injury. J Neurotrauma 2016;33: 1292-302 CrossRef Medline

38. He X, Su F, Taccone FS, et al. Cardiovascular and microvascular responses to mild hypothermia in an ovine model. Resuscitation 2012;83:760-66 CrossRef Medline

39. Amir S, Robinson B. Fos expression in rat visual cortex induced by 
ocular input of ultraviolet light. Brain Res 1996;716:213-18 CrossRef Medline

40. Gofflot F, Chartoire N, Vasseur L, et al. Systematic gene expression mapping clusters nuclear receptors according to their function in the brain. Cell 2007;131:405-18 CrossRef Medline

41. Pérez-Martín M, Rivera P, Blanco E, et al. Environmental enrichment, age, and PPAR $\alpha$ interact to regulate proliferation in neurogenic niches. Front Neurosci 2016;10:89 CrossRef Medline

42. Knauf C, Rieusset J, Foretz M, et al. Peroxisome proliferator-activated receptor-alpha-null mice have increased white adipose tissue glucose utilization, GLUT4, and fat mass: role in liver and brain. Endocrinology 2006;147:4067-78 CrossRef Medline

43. Chakravarthy MV, Zhu Y, López M, et al. Brain fatty acid synthase activates PPARalpha to maintain energy homeostasis. J Clin Invest 2007;117:2539-52 CrossRef Medline

44. Rizvi YQ, Mehta CS, Oyekan A. Interactions of PPAR-alpha and adenosine receptors in hypoxia-induced angiogenesis. Vascul Pharmacol 2013;59:144-51 CrossRef Medline

45. Hogan AM, Virues-Ortega J, Botti AB, et al. Development of aptitude at altitude. Dev Sci 2010;13:533-44 CrossRef Medline

46. Brutsaert TD, Soria R, Caceres E, et al. Effect of developmental and ancestral high altitude exposure on chest morphology and pulmonary function in Andean and European/North American natives. Am J Hum Biol 1999;1:383-95 Medline

47. Li W, Mai X, Liu C. The default mode network and social understanding of others: what do brain connectivity studies tell us. Front Hum Neurosci 2014;8:74 CrossRef Medline

48. Raichle ME. The brain's default mode network. Annu Rev Neurosci 2015;38:433-47 CrossRef Medline

49. Sui J, Huster R, Yu Q, et al. Function-structure associations of the brain: evidence from multimodal connectivity and covariance studies. Neuroimage 2014;102:11-23 CrossRef Medline

50. Soares JM, Sampaio A, Ferreira LM, et al. Stress impact on resting state brain networks. PLoS One 2013;8:e66500 CrossRef Medline

51. Henckens MJ, van der Marel K, van der Toorn A, et al. Stress-induced alterations in large-scale functional networks of the rodent brain. Neuroimage 2015;105:312-22 CrossRef Medline

52. Lu W, Wang Z. Emotional expressivity, emotion regulation, and mood in college students: a cross-ethnic study. Social Behavior and Personality: An International Journal 2012;40:319-30 CrossRef

53. Jin D. Mental health problems and personal characters in Tibetan school children. Chinese Mental Health Journal 1989;3:257-58

54. Kang YW, Kang XW, Xie SJ. Analysis on Tibetan undergraduates' personality in inland. Chinese Journal of School Health 2012; 33:1176-79

55. Chang XD, Shi JH, Dan-Ying MA. Correlation between personality traits and coping styles for junior high school students from Tibetan in Shanghai. Medical Journal of Chinese Peoples Health 2013;25:94-97

56. Mason MF, Norton MI, Van Horn JD, et al. Wandering minds: the default network and stimulus-independent thought. Science 2007; 315:393-95 CrossRef Medline

57. Sylvester CM, Corbetta M, Raichle ME, et al. Functional network dysfunction in anxiety and anxiety disorders. Trends Neurosci 2012; 35:527-35 CrossRef Medline

58. Adelstein JS, Shehzad Z, Mennes M, et al. Personality is reflected in the brain's intrinsic functional architecture. PLoS One 2011;6: e27633 CrossRef Medline

59. Servaas MN, van der Velde J, Costafreda SG, et al. Neuroticism and the brain: a quantitative meta-analysis of neuroimaging studies investigating emotion processing. Neurosci Biobehav Rev 2013;37: 1518-29 CrossRef Medline

60. Zhang J, Liu H, Yan X, et al. Minimal effects on human memory following long-term living at moderate altitude. High Alt Med Biol 2011;12:37-43 CrossRef Medline

61. Yan X, Zhang J, Gong Q, et al. Cerebrovascular reactivity among native-raised high altitude residents: an fMRI study. $B M C$ Neurosci 2011;12:94 CrossRef Medline

62. Whittingstall K, Bernier M, Houde JC, et al. Structural network underlying visuospatial imagery in humans. Cortex 2014;56:85-98 CrossRef Medline

63. Kravitz DJ, Saleem KS, Baker CI, et al. A new neural framework for visuospatial processing. Nat Rev Neurosci 2011;12:217-30 CrossRef Medline

64. Antal A, Baudewig J, Paulus W, et al. The posterior cingulate cortex and planum temporale/parietal operculum are activated by coherent visual motion. Vis Neurosci 2008;25:17-26 CrossRef Medline

65. Fischer E, Bülthoff HH, Logothetis NK, et al. Visual motion responses in the posterior cingulate sulcus: a comparison to V5/MT and MST. Cereb Cortex 2012;22:865-76 CrossRef Medline

66. Leech R, Sharp DJ. The role of the posterior cingulate cortex in cognition and disease. Brain 2014;137:12-32 CrossRef Medline

67. Bussey TJ, Muir JL, Everitt BJ, et al. Dissociable effects of anterior and posterior cingulate cortex lesions on the acquisition of a conditional visual discrimination: facilitation of early learning vs. impairment of late learning. Behav Brain Res 1996;82:45-56 CrossRef Medline

68. Zhai L, Li Q, Wang T, et al. Altered functional connectivity density in high myopia. Behav Brain Res 2016;303:85-92 CrossRef Medline

69. Ogawa $\mathrm{K}$, Inui $\mathrm{T}$. The role of the posterior parietal cortex in drawing by copying. Neuropsychologia 2009;47:1013-22 CrossRef Medline

70. Grön G, Wunderlich AP, Spitzer M, et al. Brain activation during human navigation: gender-different neural networks as substrate of performance. Nat Neurosci 2000;3:404-08 CrossRef Medline

71. Prvulovic D, Hubl D, Sack AT, et al. Functional imaging of visuospatial processing in Alzheimer's disease. Neuroimage 2002;17:1403-14 CrossRef Medline

72. Chee MW, Chen KH, Zheng H, et al. Cognitive function and brain structure correlations in healthy elderly East Asians. Neuroimage 2009;46:257-69 CrossRef Medline

73. Goldman JG, Stebbins GT, Dinh V, et al. Visuoperceptive region atrophy independent of cognitive status in patients with Parkinson's disease with hallucinations. Brain 2014;137:849-59 CrossRef Medline

74. Paulus MP, Potterat EG, Taylor MK, et al. A neuroscience approach to optimizing brain resources for human performance in extreme environments. Neurosci Biobehav Rev 2009;33:1080-88 CrossRef Medline

75. Dani JA, Montague PR. Disrupting addiction through the loss of drug associated internal states. Nat Neurosci 2007;10:403-04 CrossRef Medline

76. Frisancho AR. Functional adaptation to high altitude hypoxia. Science 1975;187:313-19 CrossRef Medline

77. Han X, Jovicich J, Salat D, et al. Reliability of MRI-derived measurements of human cerebral cortical thickness: the effects of field strength, scanner upgrade and manufacturer. Neuroimage 2006;32: 180-94 CrossRef Medline

78. Durand-Dubief F, Belaroussi B, Armspach JP, et al. Reliability of longitudinal brain volume loss measurements between 2 sites in patients with multiple sclerosis: comparison of 7 quantification techniques. AJNR Am J Neuroradiol 2012;33:1918-24 CrossRef Medline

79. McKenzie DC, Goodman LS, Nath C, et al. Cardiovascular adaptations in Andean natives after $\mathbf{6}$ wk of exposure to sea level. $J$ Appl Physiol (1985) 1991;70:2650-55 Medline

80. Sime F, Peñaloza D, Ruiz L. Bradycardia, increased cardiac output, and reversal of pulmonary hypertension in altitude natives living at sea level. Br Heart J 1971;33:647-57 CrossRef Medline

81. Bai J, Abdul-Rahman MF, Rifkin-Graboi A, et al. Population differences in brain morphology and microstructure among Chinese, Malay, and Indian neonates. PLoS One 2012;7:e47816 CrossRef Medline 